https://helda.helsinki.fi

\title{
Lactobacillus fructivorans spoilage of tomato ketchup
}

Björkroth, Johanna

International Association for Food Protection

1997

Journal of Food Protection. 1997. 60(5): 505-509

http://hdl.handle.net/1975/554

Downloaded from Helda, University of Helsinki institutional repository.

This is an electronic reprint of the original article.

This reprint may differ from the original in pagination and typographic detail.

Please cite the original version. 
Journal of Food Protection, Vol. 60, No. 5, 1997, Pages 505-509 Copyright o, International Association of Milk, Food and Environmental Sanitarians
Reprinted with permission from Journal of Food Protection. Copyright held by the International Association for Food Protection, Des Moines, Iowa, U.S.A.

\title{
Lactobacillus fructivorans Spoilage of Tomato Ketchup
}

\author{
K. JOHANNA BJORKROTH* and HANNU J. KORKEALA \\ Department of Food and Environmental Hygiene, Faculty of Veterinary Medicine, University of Helsinki, P.O. Box 57, \\ FIN-00014, Helsinki University, Finland
}

(MS\# 96-17: Received 7 February/Accepted 20 September 1996)

\begin{abstract}
Spoilage characterized by bulging as a result of gas formation in bottled ketchup was studied. Samples produced microbial growth on MRS and Rogosa selective Lactobacillus agar. Seventy randomly selected isolates typed by using restriction endonuclease (ClaI, EcoRI, HindIII) analysis were found to have identical DNA fragment patterns in gel electrophoresis. The strain was identified as Lactobacillus fructivorans using morphological, physiological and biochemical characteristics, combined with the information obtained from ribotyping. Factors affecting growth and survival of this $L$. fructivorans strain in ketchup production were also studied. An $L$. fructivorans count of $10^{5} \mathrm{CFU} / \mathrm{g}$ resulted in spoilage of inoculated ketchup samples. Spoilage occurred only in samples incubated at 15 to $30^{\circ} \mathrm{C}$. The L. fructivorans implicated in causing spoilage demonstrated heat resistance with a $D$ value of $1.2 \mathrm{~min}$ at $65^{\circ} \mathrm{C}$. The strain did not show resistance to alkaline active chloride-containing detergent sanitizer; alkyldimethylbenzylammonium chloride and alkyldimethylethylbenzylammonium chloridecontaining sanitizer were also found to be effective antimicrobial agents.
\end{abstract}

Key words: Lactobacillus fructivorans, lactic acid bacteria, spoilage, tomato ketchup, characterization, molecular typing

Tomato ketchup is considered to be a shelf-stable product. Low $\mathrm{pH}$, addition of sodium benzoate and heating of the mixture during the manufacturing process contribute to the shelf stability of ketchup. In acidic (below pH 4.0) foods like ketchup spoilage microbes are usually found to be restricted to non-spore-forming bacteria (lactic acid bacteria), or yeasts (Saccharomyces spp. Candida spp.) or molds (Byssochlamus fulva) $(2,12,14,16,19,41,43)$. Bacillus coagulans, Clostridium pasterianum, and the Bacillus macerans- $B$. polymyxa group can also cause spoilage at $\mathrm{pH} 4.0$ to $3.8(6,19)$, but growth is retarded. Heterofermentative lactobacilli $(42,43)$ have been shown to cause gas formation in ketchup but further species identification of the spoilage strains was not performed (43) or the species characterized (42) do not exist in current taxonomy.

Despite the factors used for controlling microbial

\footnotetext{
* Author for correspondence. Tel: +358-9-708 49705; Fax: +358-9-708

49718; E-mail: Johanna.Bjorkroth@Helsinki.fi
}

growth in ketchup, in-plant spoilage of ketchup occurred inflicting considerable economic hardship on the manufacturer. Spoilage was indicated by bulging of plastic ketchup bottles as a result of gas formation. The expected shelf life of this product is 8 months. Bulging occurred after 8 weeks in bottles from several product lots. No increase in total aerobic bacteriological count or yeasts were detected in routine quality-control tests.

In this study, the isolation and identification of the spoilage strain of Lactobacillus fructivorans found in the bottled ketchup is described. This organism was first isolated from spoiled salad dressing (9) and has been reported to spoil acidic food or ethanol-containing sources, mainly mayonnaise, salad dressings, vinegar preserves, sake, dessert wines, and aperitifs $(12,18,27)$. L. fructivorans can be difficult to isolate $(9,37)$ and identification of a species of the genus Lactobacillus using classical methods of physiological testing is not always sufficient (18). Traditional microbiological methods together with rDNA typing techniques were used for characterization. Factors affecting the growth and survival of this $L$. fructivorans strain in the production plant environment were also studied.

\section{MATERIALS AND METHODS}

\section{Ketchup samples}

Eight bulging plastic bottles of ketchup, one from each of eight different manufacturing lots, were sampled. The ingredients of the ketchup were tomato puree, spices, sugar, starch, sodium benzoate, acetic acid, ascorbic acid, emulsifiers, and coloring substances. The $\mathrm{pH}$ of each lot was $3.8 \pm 0.1$. After mixing of the ingredients the lot was steam heated for $10 \mathrm{~min}$ at $85^{\circ} \mathrm{C}$. The temperature was reduced and maintained at $80^{\circ} \mathrm{C}$ for 10 to $20 \mathrm{~min}$. Excess air was removed after heat treatment. The ketchup was cooled to $15^{\circ} \mathrm{C}$ prior to bottling. The bottling line was not enclosed. During bottling, caps and empty and full bottles were briefly exposed to ambient air.

\section{Reference strains}

Type strains used for the identification of the $L$. fructivorans spoilage strain were: Lactobacillus brevis ATCC 14869, Lactobacillus buchneri ATCC 4005, Lactobacillus collinoides ATCC 27612, Lactobacillus fructivorans ATCC 8288, Lactobacillus hilgardii ATCC 8290, Weissella confusa ATCC 10881, Weissella halotolerans ATCC 35410, Weissella viridescens ATCC 12706. 


\section{Microbiological analyses}

Total plate counts of the ketchup samples were determined by using pour plates with plate count agar (Difco Laboratories, Detroit, MI, USA). Parallel plates were made for aerobic and anaerobic enumeration. The anaerobic environment was created using an anaerobic jar with an $\mathrm{H}_{2}$-plus $\mathrm{CO}_{2}$-generating kit (Oxoid Ltd, Basingstoke, UK). Parallel plates with blood agar (Columbia agar base) (GIBCO BRL, Paisley, UK) were also inoculated for aerobic and anaerobic determination. Detection of lactic acid bacteria was performed by using MRS agar (Oxoid Ltd) and Lactobacillus enumeration using Rogosa selective Lactobacillus (SL) agar (Orion Diagnostica, Espoo, Finland). MRS and Rogosa SL agar were incubated anaerobically. All plates were incubated at $30^{\circ} \mathrm{C}$. Growth was inspected after 2 days. Plates with no growth were incubated for an additional 5 days (i.e., for an incubation period of 7 days) and were inspected daily for growth.

Ten- to twenty-gram samples were also enriched for 2 days at $30^{\circ} \mathrm{C}$ in meat extract broth (Orion Diagnostica), Robertson's medium (32), and MRS broth (Difco). Meat extract broth was incubated under aerobic conditions and Robertson's and MRS broths anaerobically. If growth was not observed in 2 days incubation was continued for up to 7 days. After the enrichment the procedure described by NCFA (32) was followed. Seventy colonies from MRS and Rogosa SL agar, 35 colonies from each agar type, were randomly isolated and streaked to purity. Isolates cultured from the 8 bottles were included.

\section{Isolation of DNA, restriction endonuclease analysis (REA) and determination of $r$ RNA-coding gene restriction patterns (ribotyping)}

DNA was isolated according to the guanidium thiocyanate method of Pitcher et al. (33) modified by Björkroth and Korkeala (3) with combined mutanolysin (Sigma Chemical Company, St. Louis, MO, USA) and lysozyme (Sigma) treatment. Restriction endonuclease digestion of $5 \mu \mathrm{g}$ of DNA was done according to the manufacturer's instructions with ClaI, HindIII, EcoRI, SmaI and SacII (New England Biolabs, Beverly, MA, USA). The REA, genomic blots, and the rDNA probe for rRNA-coding gene restriction patterns (ribotypes) (17) were prepared as described by Björkroth and Korkeala (3).

\section{Determination of morphological, physiological, and biochemical characteristics}

General morphological, physiological, and biochemical characteristics were determined according to Sharpe $(35,36)$ for five isolates. Growth at 4,15 , and $45^{\circ} \mathrm{C}$ was tested as well as survival at $65^{\circ} \mathrm{C}$ for $10 \mathrm{~min}$ in MRS broth. Growth in solutions with $\mathrm{pH}$ values of $2.5,3.0,3.5,4.0,4.5,5.0,5.5$, and 6.2 , with ethanol concentrations of $5 \%, 10 \%$, and $15 \%$, and $\mathrm{NaCl}$ concentrations of $8 \%, 10 \%$, and $12 \%$ were also tested in MRS broth. Carbohydrate fermentation patterns were obtained with the API $50 \mathrm{CH}$ Lactobacillus identification system (Biomerieux, Marcy l'Etoile, France). The production of ammonia from arginine was observed using the method of Briggs (8). Gas production was detected in MRS broth containing Durham tubes (37).

\section{Production of spoilage in ketchup}

Sterile ketchup samples were inoculated to determine the ability of the suspected spoilage strain to cause spoilage in ketchup. Tests were performed with two $L$. fructivorans isolates. Overnight $100 \mathrm{ml}$ MRS broth cultures were used to inoculate $50 \mathrm{~g}$ ketchup samples. The inoculated samples were incubated for 22 days at 5 , $10,15,20,25,30,37$, and $42^{\circ} \mathrm{C}$. Sensory evaluation, preformed by 5 judges as described by Korkeala et al. (22), and microbial counts on MRS agar were performed immediately and after 2, 5, 12, and 22 days.

\section{European suspension test}

The European suspension test was performed for two of the L. fructivorans isolates according to the procedure of Council of Europe (11), with modifications concerning agar media as described by Mäkelä et al. (26). The commercial detergent sanitizer and sanitizer used in the plant were tested. Detergent sanitizer was a foam-forming, alkaline (buffered to $\mathrm{pH} 12$ ), and 12 to $13 \%$ active chloride-containing concentrate. The plant sanitizer contained antimicrobial compounds of $4.5 \%$ alkyldimethylbenzylammonium chloride and $4.5 \%$ alkyldimethylethylbenzylammonium chloride. Both the detergent sanitizer and the sanitizer were diluted for use into $1 \%(\mathrm{vol} / \mathrm{vol})$ solutions.

\section{Determination of $\mathrm{D}$ values}

$D$ values were determined for one spoilage isolate and for one Lactobacillus fructivorans type strain (ATCC 8288) in sterile ketchup at $65^{\circ} \mathrm{C}$ and at $72^{\circ} \mathrm{C}$ using the open-tube-method $(41)$. REA was performed for 40 randomly selected colonies from the plates inoculated during heat inactivation testing to ensure that the growing bacteria were the same as the inoculated strain.

\section{RESULTS}

All 8 bottles showed strong gas formation and had a pungent odor. The typical $\mathrm{pH}$ value of this product is $3.8 \pm$ 0.1 . The 8 sample bottles had $\mathrm{pH}$ values of 3.3 to 3.4 . Growth was not detected on directly cultured PCA plates or blood agar, in enriched meat extract or Robertson's broths. Colonies were detected on directly cultured MRS and Rogosa SL agar media from the ketchup of all 8 bottles. The parallel enriched MRS broths showed growth as well. Directly cultured MRS plates showed growth of $3 \times 10^{5}$ to $9 \times 10^{6} \mathrm{CFU} / \mathrm{g}$ and on Rogosa SL plates $2 \times 10^{5}$ to $1 \times 10^{7}$ $\mathrm{CFU} / \mathrm{g}$. Microbiological counts of all the ketchup samples were very similar on parallel MRS and Rogosa SL agar media, suggesting Lactobacillus spp. growth.

The ClaI, EcoRI and HindIII digests of all 70 isolates were identical. REAs generated by SmaI and SacII digests did not produce suitable patterns for characterization of these strains. The general morphological, physiological, and biochemical characteristics of the isolates were: grampositive, thin rods, strong gas production from glucose, and able to use a very limited spectrum of carbohydrates: only ribose, D-fructose, D-glucose, and gluconate were fermented. Growth was observed at $15^{\circ} \mathrm{C}$ but not at 4 or $45^{\circ} \mathrm{C}$. Survival tests were positive for $10 \mathrm{~min}$ at $65^{\circ} \mathrm{C}$. Ammonia was produced from arginine and growth was observed in $8 \%$ $\mathrm{NaCl}$ concentration, but not in $10 \% \mathrm{NaCl}$-containing broth. Optimal $\mathrm{pH}$ values favorable for growth of the spoilage strain were 4.5 to 5.5 ; growth was not detected below $\mathrm{pH}$ 3.5. Isolates grew weakly on MRS agar and in MRS broth $(\mathrm{pH}$ 6). Subcultivation of the clones resulted in better growth. Isolates and the $L$. fructivorans type strain grew in MRS broth containing 5\%, $10 \%$, and $15 \%$ ethanol.

An $L$. fructivorans strain was suspected to be the cause of spoilage resulting in the bulged ketchup bottles. The identification was confirmed by comparing the ribotypes of 
the spoilage strain with corresponding patterns of heterofermentative Lactobacillus type strains that are biochemically or genetically close to $L$. fructivorans. These results (Fig. 1a, lanes 1, 2, 10, and 11; Fig. $1 \mathrm{~b}$ lanes 1 and 2) showed that the ketchup isolates and the $L$. fructivorans type strain had very similar ribotypes generated by ClaI, EcoRI, and HindIII digests. Only ClaI digests generated different patterns between the type strain and ketchup isolates (Fig. 1a, lanes 1 and 2). $L$. fructivorans REA patterns were clearly distinguished from the patterns of the other type strains studied.

The $L$. fructivorans isolates used for inoculation produced characteristic spoilage changes in 3 weeks when incubated at 15 to $25^{\circ} \mathrm{C}$. Test samples incubated at $30^{\circ} \mathrm{C}$ already showed spoilage changes after 2 weeks. Samples were deemed unfit for human consumption when bacterial counts reached $10^{5} \mathrm{CFU} / \mathrm{g}$ on MRS agar. Spoilage was not detected in test samples incubated at 5 and $10^{\circ} \mathrm{C}$. Samples incubated at $42^{\circ} \mathrm{C}$ showed $90 \%$ reduction of colonies after 3

\section{$\begin{array}{lllllllllllllllllll}1 & 2 & 3 & 4 & 5 & 6 & 7 & 8 & 9 & 10 & 11 & 12 & 13 & 14 & 15 & 16 & 17 & 18 & \text { bp }\end{array}$}
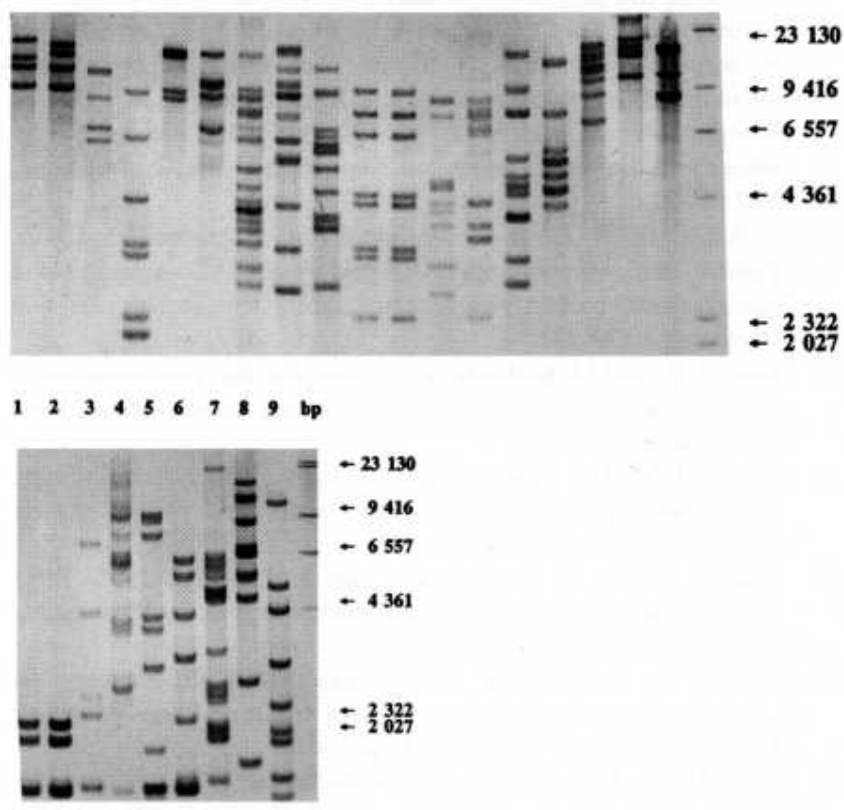

FIGURE 1a. Ribotypes obtained by Clal (lanes 1 to 9) and EcoRI (lanes 10 to 18) digests of the spoilage strain and the reference strains. Phage lambda DNA cleaved with HindIII was used as a fragment size marker. Lanes 1 and 10, the ketchup-spoilage strain; lanes 2 and 11, Lactobacillus fructivorans ATCC 8288; lanes 3 and 12, Lactobacillus buchneri ATCC 4005; lanes 4 and 13, Lactobacillus brevis ATCC 14869; lanes 5 and 14, Lactobacillus collinoides ATCC 27612; lanes 6 and 15, Lactobacillus hilgardii ATCC 8290; lanes 7 and 16, Weissella confusa ATCC 10881; lanes 8 and 17, Weissella halotolerans ATCC 35410; lanes 9 and 18, Weissella viridescens ATCC 12706. FIGURE 1b. Ribotypes obtained by HindIII digests of the spoilage strain and the reference strains. Phage lambda DNA cleaved with HindIII was used as a fragment size marker. Lane 1, the ketchup-spoilage strain; lane 2, Lactobacillus fructivorans ATCC 8288; lane 3, Lactobacillus buchneri ATCC 4005; lane 4, Lactobacillus brevis ATCC 14869; lane 5, Lactobacillus collinoides ATCC 27612; lane 6, Lactobacillus hilgardii ATCC 8290; lane 7, Weissella confusa ATCC 10881; lane 8, Weissella halotolerans ATCC 35410; lane 9, Weissella viridescens ATCC 12706. days. The same reduction was observed after 5 days at $37^{\circ} \mathrm{C}$. In the European suspension test both the detergent sanitizer and the plant sanitizer were found to be very effective (microbicidal effect, ME, was 8) on L. fructivorans strain causing spoilage.

Heat-inactivation kinetics of the spoilage strain and the type strain resembled each other. For the spoilage isolate, a $D_{65}$ of $1.2 \mathrm{~min}$ and a $D_{72}$ of $0.4 \mathrm{~min}$ were obtained in ketchup. Corresponding values for the $L$. fructivorans ATCC 8288 were $D_{65}, 0.9 \mathrm{~min}$ and $D_{72}, 0.4 \mathrm{~min}$. These values were calculated from the log-linear parts of the inactivation patterns. However, a clear tail was noticed in all inactivation curves when testing was continued. In the beginning of the test there were $10^{8}$ to $10^{9} \mathrm{CFU} / \mathrm{g}$ of inoculated ketchup. At $65^{\circ} \mathrm{C}$ tailing started after reduction of 3 to $4 \log$ cycles and at $72^{\circ} \mathrm{C}$ the same effect was noticed after reduction of 4 to $5 \mathrm{log}$ cycles. Forty strains analyzed by REA all shared the same pattern as the inoculant.

\section{DISCUSSION}

L. fructivorans strains are fastidious on primary isolation $(18,27)$, resulting in detection difficulties when PCA or blood-agar media are used. Depending on the source of isolation, mevalonic acid, tomato juice, and/or ethanol are required for growth (18). Modified MRS medium or other media designed for heterofermentative lactobacilli may provide better growth conditions $(15,40,44)$. Strains from nonalcoholic sources are known to become less fastidious during laboratory transfers and to start growing well in basic MRS broth (18). This phenomenon was also noticed with the original strains isolated from ketchup. High preincubation temperatures used in the quality control of preserved food prior to microbiological analyses also contribute to difficulties in detection of $L$. fructivorans. For fully preserved canned foods, preincubation at $30^{\circ} \mathrm{C}$ for 14 days has been recommended (32). Bulging was not present in test bottles incubated over 8 weeks at $37^{\circ} \mathrm{C}$ at the manufacturing plant. In our inoculation test, a 5-day incubation period at $37^{\circ} \mathrm{C}$ reduced $90 \%$ of inoculated $L$. fructivorans cells.

Lactic acid bacteria are not generally considered to be heat resistant. In meat-processing plants, lactic acid bacteria contamination leading to spoilage problems, with the exception of that caused by Weissella viridescens $(7,28,30,31)$, is usually considered a post-heat-treatment issue $(7,13,21,23$, $24,25,29,30$ ). Due to the layout of the ketchup-processing line, post-heat-treatment contamination during cooling and packaging was possible. $L$. fructivorans has been reported to be more heat resistant than other lactic acid bacteria tested $(38,39)$. Splittstoesser et al. (39) established a $D$ value of 1.7 min at $60^{\circ} \mathrm{C}$ for an $L$. fructivorans strain in $12 \%$ ethanol wine originally isolated from a spoiled, premixed Bloody Mary cocktail. This $D$ value is close to the $1.2-\min D_{65}$ value of the ketchup spoilage strain determined in this study. Due to the strong tailing effect noticed in $D_{65}$ and $D_{72}$ plots, the $D$ value evaluation must be considered an estimation. Biphasic destruction of $L$. fructivorans has also been observed before (38). $D$ values for the second phase, following a reduction of about $4 \log$ cycles, ranged from 4 to $6 \mathrm{~min}$ at $60^{\circ} \mathrm{C}$. It is 
difficult to determine if the heat treatment used in the ketchup processing entirely destroys the spoilage-causing $L$. fructivorans strain, especially when the level of initial contamination was unknown. Tomato juice is also known to have factors associated with heat resistance of lactic acid bacteria (20). Pectins were found to be the main tomato juice constituents protecting Lactobacillus fermentum cells against heat $(20)$.

Species identification of $L$. fructivorans is considered to be difficult using traditional phenotypic markers $(1,15,18)$. High tolerance to ethanol, a limited spectrum of fermentable carbohydrates and pronounced acidophily are characteristics typical for both $L$. fructivorans and Lactobacillus hilgardii. Lactobacillus suebicus is very tolerant to ethanol and low $\mathrm{pH}$ and ferments a broad spectrum of carbohydrates; it is genotypically closely related to Lactobacillus vaccinosterus (10). Ribotyping can be of great help in species identification $(4,17,34)$. Molecular typing techniques such as REA and ribotyping can also be excellent tools for industrial contamination analysis $(3,4,5)$. These methods can provide information concerning spoilage by revealing the nature of the contamination. The spoilage described here was eradicated by increased sanitizing of the production line using the substances found to be effective against the causative L. fructivorans strain.

\section{ACKNOWLEDGMENTS}

This work was supported by a grant from the Leo and Regina Wainstein Foundation. The authors wish to thank Mr. Scott Keller for his reading of the manuscript. Thanks are also due to Mrs. Sirkka Ekström, Ms. Mirja Eerikäinen and Mr. Pauli Hill for their technical assistance.

\section{REFERENCES}

1. Adams, M. R., P. J. O'Brien, and G. T. Taylor. 1989. Effect of the ethanol content of beer on the heat resistance of a spoilage Lactobacillus. J. Appl. Bacteriol. 66:491-495.

2. Baumgard, J., B. Weber, and B. Hanekamp. 1983. Microbiologische stabilität von Feinkosterzeugnissen. Fleischwirtschaft 63:93-94.

3. Björkroth, J., and H. Korkeala. 1996. Evaluation of Lactobacillus sake contamination in vacuum-packaged sliced cooked meat products by ribotyping. J. Food Prot. 59:398-401.

4. Björkroth, J., and H. Korkeala. 1996. rRNA gene restriction patterns as a characterization tool for Lactobacillus sake strains producing ropy slime. Int. J. Food Microbiol. 30:293-392.

5. Björkroth, J., J. Ridell, and H. Korkeala. 1996. Characterization of Lactobacillus sake strains associated with production of ropy slime by randomly amplified polymorphic DNA (RAPD) and pulsed-field gel electrophoresis (PFGE) patterns. Int. J. Food Microbiol. 31:59-68.

6. Blocher, J. C., and F. F. Busta. 1983. Bacterial spore resistance to acid. Food Technol. 37:87-89.

7. Borch, E., E. Nerbrink, and P. Svensson. 1988. Identification of major contamination sources during processing of emulsion sausage. Int. J. Food Microbiol. 7:317-330.

8. Briggs, M. 1953. The classification of lactobacilli by means of physiological tests. J. Appl. Bacteriol. 54:45-56.

9. Chariton, D. B., F. E. Nelson, and C. H. Werkman. 1934. Physiology of Lactobacillus fructivorans sp. nov. isolated from spoiled salad dressing, lowa State J. Sci. 9:1-11.

10. Collins, M. D., U. M. Rodrigues, C. Ash, M. Aguirre, J. A. E. Farrow, A. Martinez-Murcia, B. A. Phillips, A. M. Williams, and S. Wallbanks. 1991. Phylogenetic analysis of the genus Lactobacillus and related lactic acid bacteria as determined by reverse transcriptase sequencing of 16S rRNA. FEMS Microbiol. Lett. 77:5-12.
11. Council of Europe. 1987. Test methods for the antimicrobial activity of disinfectants in food hygiene. Council of Europe Publication, Strasbourg, France.

12. Dakin, J. C., and J. Y. Radwell. 1971. Lactobacilli causing spoilage of acetic acid preserves. J. Appl. Bact. 34:541-545.

13. Dykes, G. A., T. E. Cloete, and A. von Holy. 1991. Quantification of microbiological populations associated with the manufacture of vacuum-packaged, smoked Vienna sausages. Int. J. Food. Microbiol. 13:239-248.

14. EHEDG (European Hygienic Equipment Design Group), 1993. The microbiologically safe continuous thermal sterilization of liquid foods. Trends Food Sci. Technol. 4:115.

15. Gillet, I. A. 1989. Die practishe Identifizierung bierschäcdlicher Bakterien. Monatssch. Brauwiss. 12:468-475.

16. Graumlic, T. R., J. E. Marcy, and J. P. Adams, 1986. Aseptically packaged orange juice and concentrate: a review of the influences of processing and packaging conditions of quality. J. Agric. Food Chem. $34: 402-405$.

17. Grimont, F., and P. A. D. Grimont. 1986. Ribosomal ribonucleic acid gene restriction as potential taxonomic tools. Ann. Inst. Pasteur/ Microbiol. 137B:165-175.

18. Hammes, W. P., and R. F. Vogel. 1995. The genus Lactobacillus, p. 19-54. In B. J. B. Wood and W. H. Holzapfel (ed.), The genera of lactic acid bacteria. Blackie Academic and Professional, Glasgow.

19. Hersom, A. C., and E. D. Hulland. 1980. Canned food, thermal processing and microbiology. Churchill Livingstone, Edinburgh.

20. Juven, B. J., N. Ben-Shalom, and H. Weisslowicz. 1983. Identification of chemical constituents of tomato juice which affect the heat resistance of Lactobacillus fermentum. J. Appl. Bact. 54:335-338.

21. Kempton, A. G., and S. R. Bobier. 1970. Bacterial growth in refrigerated, vacuum-packed luncheon meats. Can. J. Microbiol. 16:287-297.

22. Korkeala, H., S. Lindroth, M. Suihko, A. Kuhmonen, and P.-L. Penttilä. 1985. Microbiological and sensory quality changes in blood pancakes and cooked ring sausage during storage. Int. J. Food Microbiol. 2:279-292.

23. Mäkelä, P., and H. Korkeala. 1987. Lactobacillus contamination of cooked ring sausages at sausage processing plants. Int. J. Food Microbiol. 5:323-330.

24. Mäkelă, P. M., H. J. Korkeala, and J. J. Laine. 1992. Survival of ropy slime producing lactic acid bacteria in heat processes used in the meat industry. Meat Sci. 31:463-471.

25. Mäkelä, P. M., H. J. Korkeala, and J. J. Laine. 1992. Ropy slime-producing lactic acid bacteria contamination at meat processing plants. Int. J. Food Microbiol. 17:27-35

26. Mäkelä, P., H. Korkeala, and K. Sand. 1991. Effectiveness of commercial germicide products against the ropy slime producing lactic acid bacteria. J. Food Prot. 58:632-636.

27. Meyer, R. S., M. A. Grant, L. O. Luedecke, and H. K. Leung. 1989. Effects of $\mathrm{pH}$ and water activity on microbiological stability of salad dressing. J. Food Prot. 52:477-479.

28. Milbourne, K. 1983. Thermal tolerance of Lactobacillus viridescens in ham. Meat Sci. 9:113-119.

29. Mol, J. H. H., J. E. A. Hietbring, H. W. M. Mollen, and J, van Tinteren. 1971. Observations on the microflora of vacuum packaged sliced cooked meat products. J. Appl. Bacteriol. 34:377-397. 48-51.

30. Nerbrink, E., and E. Borch. 1993. Evaluation of bacterial contamination at separate processing stages in emulsion sausage production. Int. J. Food Microbiol. 20:37-44.

31. Niven, C. F., Jr., L. G. Buttner, and J. B. Evans. 1954. Thermal tolerance studies on the heterofermentative lactobacilli that cause greening of cured meat products. Appl. Microbiol. 2:26-29.

32. Nordic Committee on Food Analysis. 1991. Microbiological examination of fully preserved canned foods, Report no. 59. NCFA. Espoo, Finland.

33. Pitcher, D. G., N. A. Saunders, and R. J. Owen. 1989. Rapid extraction of bacterial genomic DNA with guanidium thiocyanate. Lett. Appl. Microbiol. 8:151-156.

34. Schleifer, K. H., W. Ludwig, and R. Amann. 1994. Nucleic acid probes, ch. p. 463-510. In M. Goodfellow and A. G. O'Donnel (ed.). Handbook of new bacterial systematics. Academic Press Ltd, London.

35. Sharpe, M. E. 1962. Taxonomy of the lactobacilli. Dairy Sci. Abstr. 24:109-118. 
36. Sharpe, M. E. 1979. Identification of the lactic acid bacteria, p. 233-259. In F. A. Skinner and D. W. Lovelock (ed.), Identification methods for microbiologists. Academic Press, London.

37. Smittle, R. B., and M. C. Cirigliano. 1992. Salad dressings, p. 975-983. In C. Vanderzandt and D. F. Splittstoesser (ed.), Compendium of methods for the microbiological examination of foods. American Public Health Association, Washington, D.C.

38. Splittstoesser, D. F. 1981. Microorganisms involved in the spoilage of fermented fruit juices. J. Food Prot. 45:874-877.

39. Splittoesser, D. F., L. L. Lienk, M. Wilkinson, and J. R. Stamer. 1975. Influence of wine composition on the heat resistance of potential spoilage organisms. Appl. Microbiol. 30:369-373.

40. Stead, D. 1993. The effect of chlorogenic, gallic and quinic acids on the growth of spoilage strains of Lactobacillus collinoides and Lactobacillus brevis. Lett. Appl. Microbiol. 18:112-114.

41. Stumbo, C. R. 1973. Thermobacteriology and food processing. Academic press, New York.

42. Tanner, F. W. 1944. Microbiology of tomato products, p. 655-692. In The microbiology of foods. Garard Press, Champaign, IL.

43. Tjaberg, T. B., and L. Rossebo. 1969. Heterofermentative lactobacilli as cause of blowing of plastic bottles containing tomato ketchup. Medlemsblad Norske Veterinärförening 21:476-478.

44. Vogel, R. F., G. Böcker, P. Stolz, M. Ehrmann, D. Fanta, W. Ludwig, B. Pot, K. Kerstens, K. H. Schleifer, and W. P. Hammes. 1994. Identification of lactobacilli from sourdough and description of Lactobacillus pontis sp. nov. Int. J. Syst. Bact. 44:223-229. 